\title{
Geometrical aspects of the energetic effectiveness of huddling in small mammals
}

\author{
Mauricio CANALS, Mario ROSENMANN and Francisco BOZINOVIC*
}

Canals M., Rosenmann M. and Bozinovic F. 1997. Geometrical aspects of the energetic effectiveness of huddling in small mammals. Acta Theriologica 42: 321-328.

Reduced energy expenditure resulting from huddling in small mammals is mainly attributed to the reduced surface area/volume ratio of the huddling group. Here we propose a model to account for the reduction of the relative exposed area of grouped animals and for the diminution of metabolic rate during huddling. We attempt to explain mechanistically how changes in energy savings may operate. We applied our model to results obtained by grouping deformable bodies, and also laboratory measurements of oxygen consumption on huddling small mammals of four species. We found a small amount of diversity in the energetic efficiency of huddling. We estimate that the average relative area lost during huddling ranged between 28.7 and $39.1 \%$. The average huddling effectiveness in the studied species was $42 \%$, which is a significant fraction of the energy/matter budget of a small mammal, especially under winter conditions.

Departamento de Ciencias Biológicas, Facultad de Ciencias Veterinarias, Universidad de Chile, Casilla 2, Correo 15, Santiago, Chile (MC); Departamento de Ciencias Ecológicas, Facultad de Ciencias, Universidad de Chile, Casilla 653, Santiago, Chile (MR); Departamento de Ecología, Facultad de Ciencias Biológicas, P. Universidad Católica de Chile, Casilla 114-D, Santiago, Chile; e-mail: fbozinov@genes.bio.puc.cl, fax: (56-2) 686-2621 (FB)

Key words: huddling, energy saving, models, behavioural thermoregulation

\section{Introduction}

An important behavioral strategy of winter active small mammals is winter aggregation, a behavior in which individuals share a small space for period of days or months (West and Dublin 1984). Several factors facilitate the tendency to aggregate under winter conditions, the most important are: reproductive cessation, reduced aggression, clumped food resources, and low ambient temperatures. One of the most relevant behavioral adaptations that increase winter survival is probably huddling (Sealander 1952). Huddling is effective in decreasing metabolic heat production and maintenance cost (Górecki 1968, Gębczyński 1969, Gębczyńska 1970, Gębczyńska and Gębczyński 1971, Tertil 1972, Andrews and Belknap 1986, Bozinovic et al. 1988), increasing energy saving and hence survival (Sealander 1952, Fedyk 1971).

*To whom all correspondence should be addressed. 
Reduced energy expenditure is mainly attributed to the reduced surface area/volume ratio of the huddling group (Contreras 1984). Based on a geometrical approach, here we propose a model to account for the reduction of the relative exposed area of grouped animals and for the diminution of metabolic rate during huddling. We attempt to explain mechanistically how changes in energy savings may operate. We applied our model to results obtained by grouping deformable bodies, and also laboratory experiments on huddling in small mammals.

The individual metabolic rate (MR) is a function of the individual exposed area (Kleiber 1961), being expressed as:

$$
\mathrm{MR}=\mathrm{m} \mathrm{A}^{v}
$$

and, during huddling, the metabolic rate can be described (Canals et al. 1989) as:

$$
\mathrm{MRh}_{\mathrm{h}}=\mathrm{mh} \mathrm{Ah}^{v}
$$

where $m$ is a factor that depends on the thermal gradient $\left(T_{B}-T_{A}\right)$, with $T_{B}-$ body temperature, $\mathrm{T}_{\mathrm{A}}$ - ambient temperature; and $v$ is an empirical exponent. On the other hand, $M R_{h}, m_{h}$ and $A_{h}$, are equivalent to the normal (ungrouped) values of $M R, m$ and $A$ respectively. Then, the metabolic ratio $\left(R_{m}\right)$ of huddling/non-huddling animals is:

or

$$
\begin{array}{ll} 
& R_{m}=M R_{h} / M R=\left(m_{h} / m\right) R_{a}{ }^{v} \\
\text { being, } & R_{a}=A_{h} / A \\
& R_{m}=f(n) R_{a}{ }^{v}
\end{array}
$$

Here, $f(n)=m_{h} / m$, is a factor that depends on the number of grouped individuals, and on modifications in $\left(\mathrm{T}_{\mathrm{B}}-\mathrm{T}_{\mathrm{A}}\right)$, as a consequence of metabolic changes of huddled individuals (see Martin et al. 1980), or effects of grouped animals on the local microclimate (Hayes et al. 1992).

To explore $R_{\mathrm{a}}$ during huddling we considered that a small mammal can be modeled as a sphere with radius $R_{1}$. The area of our model is $A_{h 1}=4 \pi R_{1}^{2}$. Thus, when two individuals (represented by deformable spheres) are grouped, the total exposed area can be described as:

$$
\mathrm{A}_{\mathrm{h} 2}=4 \pi \mathrm{R}_{1}^{2}-\mathrm{a}_{1}+4 \pi \mathrm{R}_{2}^{2}-\mathrm{a}_{2}
$$

with $R_{1}$ and $R_{2}$ the radius of the spheres, and $a_{1}$ and a2 the area lost from spheres 1 and 2 during contact (in this case $\mathrm{a}_{1}=\mathrm{a}_{2}$ ). Assuming that animals tend to reduce a maximal area " $a$ " during each contact, which is at the same time limited by organismal constraints to deformation, a third grouping individual will add $4 \pi R_{2}{ }^{2}-a_{3}$ to the total exposed area and cover a3 areas, then:

$$
\begin{array}{ll} 
& \mathrm{A}_{\mathrm{h} 3}=4 \pi\left(\mathrm{R}_{1}{ }^{2}+\mathrm{R}_{2}{ }^{2}+\mathrm{R}_{3}{ }^{2}\right)-2\left(\mathrm{a}_{2}+\mathrm{a}_{3}\right) \\
\text { and } & \mathrm{A}_{\mathrm{hn}}=4 \pi \sum_{i=1}^{i=n} \mathrm{R}_{1}{ }^{2}-2 \sum_{i=2}^{i=n} \mathrm{a}_{\mathrm{i}} \\
\text { or } & \mathrm{A}_{\mathrm{hn}}=\mathrm{n}\left(4 \pi \overline{\mathrm{R}}^{2}\right)-(\mathrm{n}-1) 2 \overline{\mathrm{a}},
\end{array}
$$


with $\bar{R}$ the average radius of the spheres and $\bar{a}$ the average area that is lost by the individuals during huddling.

The area of $n$ non-grouped spheres is $A_{n}=n 4 \bar{R}^{2}$, then the area ratio of grouped/non grouped spheres is:

$$
R_{\mathrm{a}}=\mathrm{A}_{\mathrm{hn}} / \mathrm{A}_{\mathrm{n}}=\phi(1 / \mathrm{n})+(1-\phi),
$$

with $\phi=2 \overline{\mathrm{a}} /\left(4 \pi \overline{\mathrm{R}}^{2}\right)$ which represents twice the average relative area that is lost by grouped individuals, that is, double the average area lost divided by the average area of individuals $\left(A_{1}\right)$. As the values of $\phi$ will depend on how closely grouped individuals can hold themselves together, we called $\phi$ the "deformation coefficient". In general terms $\phi=2$ a / A. We arrive to the same relation if we used deformable cylinders or prisms as our models. In the first case:

$$
\phi=2 \mathrm{a} /\left(2 \pi \overline{\mathrm{R}}^{2}+2 \pi \mathrm{R}_{\mathrm{h}}\right)=2 \mathrm{a} / \mathrm{A}_{1}
$$

where $\mathrm{h}$ is the average length of the cylinder; and for right prisms of polygonal basis in which:

$$
\phi=4 \alpha \sin (\pi / N) /\{\mathrm{N} \sin (2 \pi / N)+2 \mathrm{~N} \alpha \sin (\pi / N)\}=2 \mathrm{a} / \mathrm{A}_{1}
$$

where $\alpha$ is the ratio between prisms' length and the radius of the circumference circumscribing the basis of the prisms (Canals et al. 1989).

Combining (1) and (2) yields:

$$
R_{m}=f(n)\{\phi(1 / n)+(1-\phi)\}^{v}
$$

\section{Methods}

To test the $R_{a}$ model goodness of fit (equation 2) we used plastic bags as models of small mammals deformable bodies. Several groups of plastic bags $(6.2 \times 19.3 \mathrm{~cm})$ were used as dummies. Bags were filled with $200 \mathrm{ml}$ of fine sand and closed a the tops. On each group, the exposed area $\left(\mathrm{A}_{\mathrm{h}}\right)$ was compared with the area of the same number of ungrouped bags (A) and then, $R_{a}$ was computed. The area A was calculated from: $\mathrm{A}=2 \times \mathrm{n} \times 6.2 \times 19.3=239.3 \times \mathrm{n}\left(\mathrm{cm}^{2}\right)$, where $\mathrm{n}$ is the number of bags. Grouped of piled and in one layer bags were spray painted, so that the contact area among them $\left(\mathrm{A}_{\mathrm{i}}\right)$, remained uncoloured. This area was estimated after cutting and weighing $( \pm 0.0001 \mathrm{~g})$ the uncoloured sections. The exposed area was calculated by the expression: $A_{h}=A-A_{i}$. To test the goodness of fit of equation (2) we used linear regression analysis. A Student $t$-test was used to compare the relative area lost when two bodies are in contact against our empirical values (a / $\mathrm{A}=\phi / 2)$.

Before testing the goodness of fit of our $R_{m}$ model (equation 3 ), we first calculated an expected $v$-exponent by combining the classical relationship for metabolic rate (McNab 1980):

$$
\mathrm{MR}=\mathrm{C}\left(\mathrm{T}_{\mathrm{B}}-\mathrm{T}_{\mathrm{A}}\right) \text {, }
$$

where $\mathrm{C}$ - thermal conductance, $\mathrm{T}_{\mathrm{B}}$ - body temperature, and $\mathrm{T}_{\mathrm{A}}$ - ambient temperature; with the allometric relationship $\mathrm{C}-3.4 \mathrm{M}_{\mathrm{B}}{ }^{0.49}$ (Herreid and Kessel 1967), in which $\mathrm{M}_{\mathrm{B}}$ - body mass, and $\mathrm{A} /\left(\mathrm{V}^{2 / 3}\right.$ ) - $\mathrm{k}$, where $\mathrm{A}$ - area and $\mathrm{V}-$ volume (Kleiber 1961), arrive to the exponent $v=0.735$. Then the equation (3) becomes:

$$
R_{m}=f(n)\{\phi(1 / n)+(1-\phi)\}^{0.735}
$$

To test the goodness of fit of our $\mathrm{R}_{\mathrm{m}}$ model (equation 3 ), four species of small rodents were studied. The laboratory mice Mus musculus (Linnaeus, 1758), $n=29\left(\mathrm{M}_{\mathrm{B}}=24.7 \pm 5.0 \mathrm{~g}\right.$ ) and three wild species from our colony including the South American cricetid rodents Eligmodontia typus puerulus (Cuvier, 
1837), $n=12\left(\mathrm{M}_{\mathrm{B}}=22.6 \pm 3.2 \mathrm{~g}\right) ;$ Abrothrix lanosus (Thomas, 1897), $n=11\left(\mathrm{M}_{\mathrm{B}}=21.4 \pm 5.2 \mathrm{~g}\right)$ and A. andinus (Philippi, 1858), $n=10\left(\mathrm{M}_{\mathrm{B}}=34.6 \pm 3.5 \mathrm{~g}\right.$ ) were used. In addition, we reanalyzed our reported data (Bozinovic et al. 1988) for the cricetid Phyllotis darwini (Waterhouse, 1837), ( $\mathrm{M}_{\mathrm{B}}=53.2$ $\pm 12.0 \mathrm{~g}$ ), and the didelphid marsupial Thylamys elegans (Waterhouse, 1838), $\left(\mathrm{M}_{\mathrm{B}}=27.3 \pm 5.3 \mathrm{~g}\right.$ ) (Canals et al. 1989). In the experiments, energy expenditure was estimated by measurements of oxygen consumption. Each trial was conducted during $2-8 \mathrm{~h}$ at different ambient temperatures and in several specific groups, by using a closed circuit automatic-computerized respirometer based on Morrison (1951). The statistics used were regression analyses of our model applied to all the examined species. Considering $f(n)=1$ we obtain: $R_{m}=(\phi / n+c)^{0.735}$. It should be noted that this equation becomes a simple linear model if we call, $x=\mathrm{R}_{\mathrm{m}} 1 / 0.735$ and $y=1 / \mathrm{n}$, then $x=\phi y+\mathrm{c}$. Thus, regression analyses are linear, being c a free parameter. $\phi$ slopes for different species were compared by ANCOVA test (Zar 1984).

\section{Results}

The reduction in the area ratio $\left(R_{a}\right)$ in these bodies is depicted in Fig. 1 . Regression analysis show that the $R_{\mathrm{a}}$ decay, fully adjust to: $\mathrm{R}_{\mathrm{a}}=0.47(1 / \mathrm{n})+0.53$, $r=0.98, F=64.57, p<0.001$.

The average relative area lost when our plastic models are in contact is 0.237 . Theoretically, we expected a $\phi$ value of $2 \times 0.237=0.475$. This figure is not statistically different $\left(\mathrm{t}_{18}=0.085, p>0.1\right.$ ) from 0.47 which was empirically obtained.

Figure 2 despicts the relationships between $R_{m}$ and $n$ for the studied species. Parameters of the obtained curves and their statistical significance are in Table 1. For all the examined species, the model fully adjust to the metabolic decay during huddling $\left(R^{2}\right.$-values ranged from 0.58 to 0.94 , see Table 1). Deformation coefficients $\phi$ ranged between 0.575 in A. lanosus to 0.783 in T. elegans. In spite of this variation, non significant differences were obtained between species (ANCOVA, $p>0.05$ ).

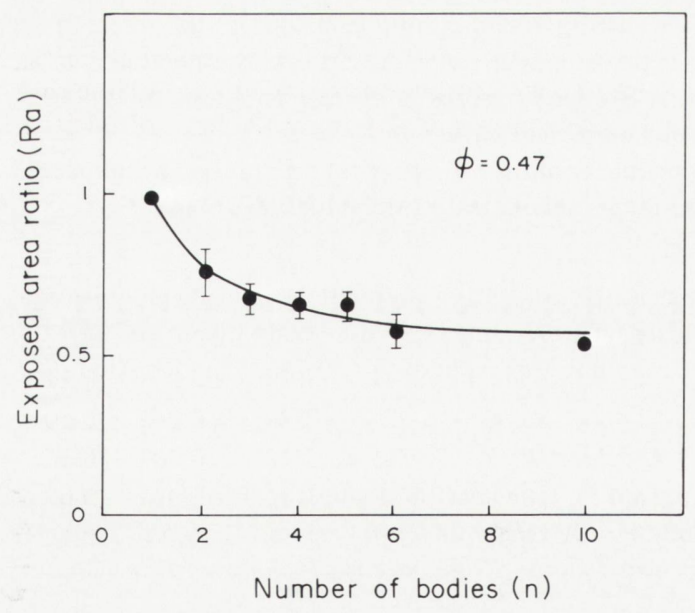

Fig. 1. Decay of area ratios in deformable bodies $\left(R_{a}\right)$ as function of their number $(n)$ (mean $\pm 1 \mathrm{SE}$ ). The solid line represents the calculated regression. 


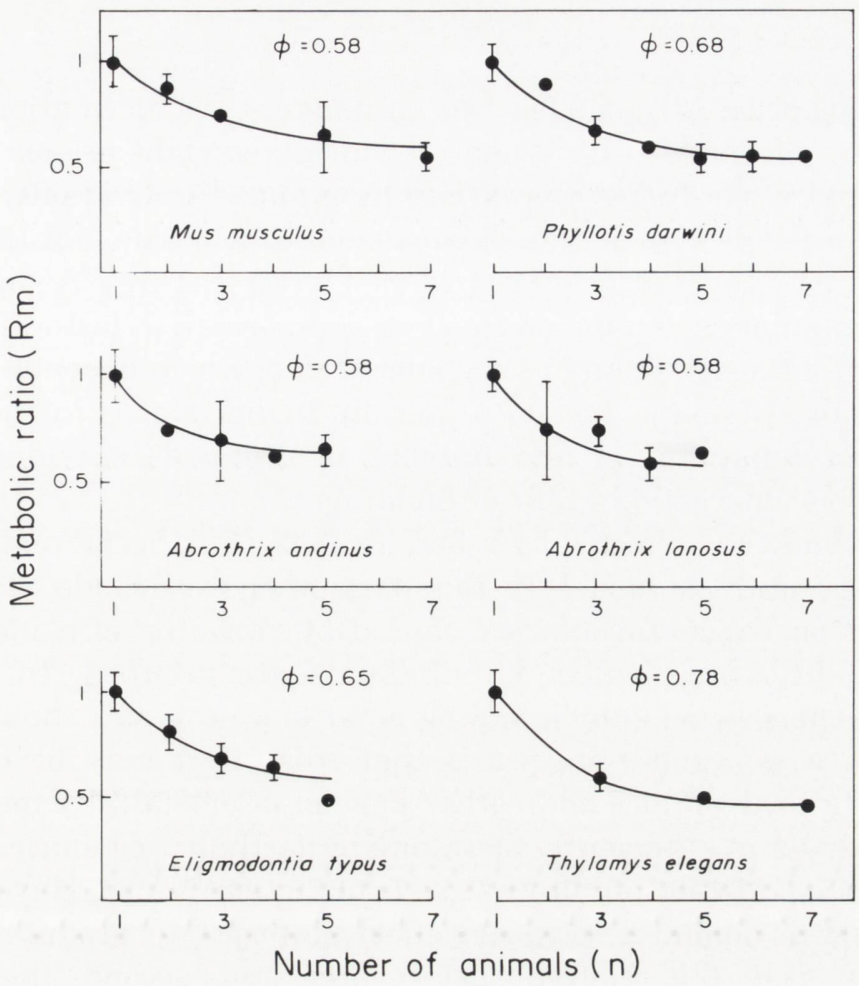

Fig. 2. Decay of metabolic ratios $\left(R_{m}\right)$ in different species of small mammals as function of the number of grouped individuals $(n)$. The deformation coefficient $(\phi)$ for each species is indicated. Symbols represent mean values $\pm 1 \mathrm{SE}$ and lines the calculated regressions.

Table 1. Parameters and regression analyses of the curve: $R_{m}=(\phi / n+c)^{0.735}$ representing the $R_{m}$ decay during huddling of studied small mammals. $\mathrm{T}_{\mathrm{A}}-$ ambient temperature at which metabolic rate was measured, $\mathrm{SE}$ - standard error, $\mathrm{S}_{X Y}$ - standard error of estimate, $R^{2}$ - determination coefficient.

\begin{tabular}{|c|c|c|c|c|c|c|c|c|}
\hline \multirow{2}{*}{ Species } & \multirow{2}{*}{$\mathrm{T}_{\mathrm{A}}\left({ }^{\circ} \mathrm{C}\right)$} & \multirow{2}{*}{$\phi \pm \mathrm{SE}$} & \multirow{2}{*}{$\mathrm{c} \pm \mathrm{SE}$} & \multirow{2}{*}{$R^{2}$} & \multicolumn{4}{|c|}{ ANOVA } \\
\hline & & & & & $F$ & $\mathrm{df}$ & $p$ & $\mathrm{~S}_{X Y}$ \\
\hline Abrothrix andinus & 12.5 & $0.58 \pm 0.12$ & $0.42 \pm 0.07$ & 0.58 & 25.1 & $1 / 8$ & $<0.001$ & 0.17 \\
\hline Abrothrix lanosus & 15.0 & $0.58 \pm 0.08$ & $0.37 \pm 0.06$ & 0.62 & 53.0 & $1 / 16$ & $<0.001$ & 0.11 \\
\hline Eligmodontia typus & 15.0 & $0.65 \pm 0.06$ & $0.36 \pm 0.04$ & 0.85 & 128.7 & $1 / 24$ & $<0.001$ & 0.10 \\
\hline Mus musculus & 15.0 & $0.58 \pm 0.12$ & $0.44 \pm 0.08$ & 0.72 & 25.4 & $1 / 10$ & $<0.001$ & 0.15 \\
\hline Phyllotis darwini & 5.0 & $0.68 \pm 0.05$ & $0.33 \pm 0.03$ & 0.94 & 168.9 & $1 / 11$ & $<0.001$ & 0.06 \\
\hline Thylamys elegans & 12.5 & $0.78 \pm 0.10$ & $0.22 \pm 0.07$ & 0.90 & 59.6 & $1 / 6$ & $<0.001$ & 0.11 \\
\hline
\end{tabular}




\section{Discussion}

Our proposed model (3) includes two parameters, a deformation coefficient $\phi$ and a dependent parameter $\mathrm{f}(\mathrm{n})$. When we considered right prisms in our model, $\phi$ represented twice the relative area lost by grouped individuals, being then a constant. In deformable bodies, this phenomenon is also true, but the area lost by a single body is not a constant, here considers a mean lost area. A similar situation occurs in small mammals, but in addition to this deformation factor (loss of exposed area), a factor of intensity should be considered in $\phi$, which depends on the degree of active huddling. Higher values of $\phi$ indicate higher slopes in the relationship between oxygen consumption and number of grouped individuals, and consequently a higher energetic benefit of huddling.

The $\mathrm{f}(\mathrm{n})$ parameter is affected by $\mathrm{n}$ and $\mathrm{T}_{\mathrm{B}}-\mathrm{T}_{\mathrm{A}}$. Furthermore, it accounts for the variability around the model. In this parameter we include the positive and negative effects on the metabolic rate caused by crowding of $\mathrm{n}$ individuals, and possible $T_{B}$ modifications when $n$ individuals are grouped. In addition, the mechanisms of energy saving by huddling is far more complex than our analyses. In fact, Martin et el. (1980) suggested that this effect may be completely independent of physical contact and rather depend on chemically mediated effects between individuals in sufficiently close proximity that they share an air supply (but see Contreras 1984 for an alternative explanation). Also, Hayes et al. (1992) suggested that two dominant physical effects interact to produce the observed energy savings: first, the reduced surface area and, second, the effect of the grouped animals on the local microclimate. The latter study concluded that only $50 \%$ of observed savings may be attributed to reduced surface effects. Based on our Table 1 and observing the $R^{2}$-values, our percentage of observed energy savings attributed to the reduced surface effect ranged from 58 to $94 \%$.

We can now compute the maximum energy saving during huddling ("huddling effectiveness" $=\mathrm{HE}_{\mathrm{E}}$ ), by considering that if $\mathrm{n} \rightarrow \infty$, we obtain the asymptote in (2), which is the metabolic value: $\mathrm{M}_{\mathrm{m}}=(1-\phi)^{0.735}$, that the huddling group is able to reach, that is:

$$
\mathrm{H}_{\mathrm{e}}=1-\mathrm{M}_{\mathrm{m}}
$$

This fact (the asymptotic value) allows us to propose that our new model is far more robust than previous reported exponential models (Contreras 1984, Canals et al. 1989) correcting the unreal tendency to $M R=0$, when the number of grouped individuals during huddling is larger.

A factual relationship can be obtained when we set $n$ equal to the mean number of individuals which produce the minimum value of $\mathrm{R}_{\mathrm{m}}$. From our empirical results, this number was $4.95 \approx 5.0$ individuals. Consequently, a realistic expression of $\mathrm{M}_{\mathrm{m}}$ is:

$$
\mathrm{M}_{\mathrm{m}}=\{\phi / 5+(1-\phi)\}^{0.735}
$$


Then, a better estimation of $\mathrm{HE}_{\mathrm{E}}$ may be obtained when the last expression of $\mathrm{M}_{\mathrm{m}}$ is used in the equation (4). In doing so, we found a small amount of diversity in the energetic efficiency of huddling. Based on this model we estimate that the average relative area lost during huddling ranged between 28.7 and $39.1 \%$. The average $\mathrm{HE}_{\mathrm{E}}$ in the studied species was $42 \%$, which is a significant fraction of the energy/matter budget of a small mammal and especially under winter conditions. This figure strengthens the survival value of the huddling behavior. In fact, if we note that $R_{m}=M_{h} / M_{0}$, where $M_{h}$ is the metabolic rate of grouped individuals and $M_{0}$ their metabolic rate when separated, it is possible to estimate, by using the equation (4), the maximal energy saved ( $E_{S}$ ) during huddling by: $E_{S}=M_{O} H_{E}$ $\left(\mathrm{mlO}_{2} / \mathrm{g} \mathrm{h}\right)$. Calculations of maximal energy saved are important because the energy balance appears to be related with the observed reduction in the rates of food intake during huddling (Springer et al. 1981). For example, in the Chilean mouse-oppossum $T$. elegans, $\mathrm{H}_{\mathrm{E}}=0.515$ (from the last equation, and using five individuals as an approach to $\left.\mathrm{M}_{\mathrm{m}}\right)$ then, $\mathrm{E}_{\mathrm{S}}=6.56 \times 0.515=3.37\left(\mathrm{mlO}_{2} / \mathrm{g} \mathrm{h}\right)$. This value implies that in a single month the maximal energy saved (assuming that animals are grouped $50 \%$ of the time) will be: $159.2 \mathrm{Kcal}$.

Acknowledgments: We thank C. Veloso and F. F. Novoa for valuable technical help. This work was funded by a Fondo Nacional de Ciencia y Tecnología (FONDECYT) grant 1950394 to F.B.

\section{References}

Andrews R. V. and Belknap R. W. 1986. Bioenergetic benefits of huddling by deer mice (Peromyscus maniculatus). Comparative Biochemistry and Physiology 85A: 775-778.

Bozinovic F., Rosenmann M and Veloso C. 1988. Termorregulación conductual en Phyllotis darwini (Rodentia: Cricetidae): efecto de la temperatura ambiente, uso de nidos y agrupamiento social sobre el gasto de energía. Revista Chilena Historia Natural 61: 81-86.

Canals M., Rosenmann M. and Bozinovic F. 1989. Energetics and geometry of huddling in small mammals. Journal of Theoretical Biology 141: 181-189.

Contreras L. C. 1984. Bioenergetics of huddling: test of a psycho-physiological hypothesis. Journal of Mammalogy 65: 256-262.

Fedyk A. 1971. Social thermoregulation in Apodemus flavicolis (Melchior, 1834). Acta Theriologica 16: 221-229.

Gębczyńska Z. 1970. Bioenergetics of a root vole population. Acta Theriologica 15: 33-66.

Gębczyńska Z. and Gębczyński M. 1971. Insulation properties of nest social temperature regulation in the bank-vole Clethrionomys glareolus. Annals Zoological Fennici 8: 104-108.

Gębczynski M. 1969. Social regulation of body temperature in the bank vole. Acta Theriologica 29: 427-440.

Górecki A. 1968. Metabolic rate and energy budget in the bank vole. Acta Theriologica 13: 341-365.

Hayes J. P., Speakman J. R. and Racey P. A. 1992. The contribution of local heating and reducing exposed surface area to the energetic benefits of huddling by short-tailed field voles. Physiological Zoology 65: 742-762.

Herreid C. F. and Kessel B. 1967. Thermal conductance in birds and mammals. Comparative Biochemistry and Physiology 21A: 405-414.

Kleiber M. 1961. The fire of life. John Wiley and Sons, New York: 1-453. 
Martin R. A., Fiorentini M. and Connors F. 1980. Social facilitation of reduced oxygen consumption in Mus musculus and Meriones unguiculatus. Comparative Biochemistry and Physiology 65A: 519-522.

McNab B. K. 1980. On estimating thermal conductance in endotherms. Physiological Zoology 53: $145-156$.

Morrison P. R. 1951. An automatic manometric respirometer. Review of Scientific Instruments 2: $264-267$.

Sealander J. A. 1952. The relationship of nest protection and huddling to survival in Peromyscus at low temperature. Ecology 33: 63-71.

Springer S. D., Gregory P. and Barrett W. 1981. Importance of social grouping on bioenergetics of the golden mouse, Ochrotomys nuttalli. Journal of Mammalogy 62: 628-630.

Tertil R. 1972. The effect of behavioural theromoregulation on the daily metabolism of Apodemus agrarius. Acta Theriologica 22: 328-332.

West S. D. and Dublin H. T. 1984. Behavioral strategies of small mammals under winter conditions: solitary or social? [In: Winter ecology of small mammals. J. F. Merritt, ed]. Special Publication of the Carnegie Museum of Natural History, Pittsburgh, PA: 293-301.

Zar J. H. 1984. Biostatistical Analysis. Prentice-Hall, Englewood Cliffs, New York: 1-718.

Received 4 November 1996, accepted 15 April 1997. 